\title{
Diretrizes para o parcelamento do solo urbano
}

\begin{abstract}
Resumo
Os dados geométricos do Cadastro Territorial e do Registro de Imóveis, do parcelamento do solo urbano no Brasil, são provenientes dos projetos aprovados pelo setor de engenharia das prefeituras, podendo ser por meio digital ou analógico, observando a dinâmica da ocupação territorial urbana ao longo do tempo, bem como a legislação e pesquisas realizadas neste tema. Percebeu-se que a principal função do cadastro territorial de garantia geométrica através dos pontos limites legais das parcelas não está sendo atendida. Portanto, definiu-se uma diretriz para o parcelamento do solo urbano, a qual poderá ser aplicada nas prefeituras para compor os procedimentos e as normas técnicas específicas para o sistema básico do CTM, de modo a atender às exigências da Portaria 511 (2009) do Ministério das Cidades e o Art. 30 da Constituição Federal (1988).
\end{abstract}

Palavras-chave: Parcelamento do solo urbano; Cadastro territorial; Como construído.
Leonel Euzébio de Paula Neto

Doutor em Engenharia Civil;

Professor no Instituto Federal de

Santa Catarina - IFSC.

Brasil

leonel@ifsc.edu.br

\section{Flavio Boscatto}

Doutor em Engenharia Civil;

Professor no Instituto Federal de

Santa Catarina - IFSC.

Brasil

flavio.boscatto@ifsc.edu.br

\section{Rovane Marcos de França}

Mestre em Engenharia Civil;

Professor no Instituto Federal de

Santa Catarina - IFSC.

Brasil

rovane@ifsc.edu.br

\section{Para citar este artigo:}

DE PAULA NETO, Leonel Euzébio; BOSCATTO, Flavio; FRANÇA, Rovane Marcos de. Diretrizes para o parcelamento do solo urbano. Revista PerCursos. Florianópolis, v. 16, n.30, p. 34 - 57. jan./abr. 2015.

DOI: $10.5965 / 1984724616302015034$

http://dx.doi.org/10.5965/1984724616302015034 


\title{
Guidelines for urban land parceling
}

\begin{abstract}
The registration of division of urban land in Brazil comes from the projects approved by the prefectures engineering sector can be by analog or digital means, in this way does not meet the primary function of which is joined to guarantee geometric points through the legal limits of the plots. So set up a guidelines for the of urban land parceling for the cadaster sectors the municipalities should perform procedures to compose the specific procedures and technical standards for the basic system of the CTM, so as to meet requirements of Ordinance 511 (2009) of the Ministry of Cities, and to Article 30 of the Federal Constitution (1988).
\end{abstract}

Keywords: Urban land parceling; cadaster; As built. 


\section{Introdução}

Pretende-se, neste artigo, demonstrar a possibilidade de uma diretriz para que o parcelamento do solo urbano atenda à Constituição Federal (1988) e à Portaria 511 (2009) do Ministério das Cidades.

Assim, deseja-se que após a aprovação do projeto de parcelamento do solo urbano pelo setor de engenharia da prefeitura, este seja encaminhado e orientado pelo Cadastro Territorial Multifinalitário - CTM, com vistas a dar início ao cadastramento das parcelas com seus respectivos pontos limites legal da propriedade. Desta maneira o cadastro atenderá as exigências da Portaria nº 511 (2009).

Somente após estes procedimentos na prefeitura, é que deverá ser enviado ao Cartório de Registro de Imóveis - CRI, para realizar a matrícula de cada parcela.

Para isto ocorrer, o setor de cadastro deve desenvolver normas e procedimentos técnicos:

Em primeiro lugar deverá ser exigida toda a documentação dos trabalhos realizados em campo, tais como os métodos de medição / implantação que devem ser utilizados, a precisão e a tolerância que devem ser atingidas e a forma como estes dados devem ser apresentados, sendo estes documentos fundamentais na garantia geométrica e física dos pontos limites legal das parcelas. Também definir como os vértices de cada parcela devem ser demarcados.

Em segundo lugar, este setor deverá disponibilizar técnicos especializados na área de medição, certificados pela prefeitura e que se responsabilizem judicialmente pela administração cadastral. Estes profissionais têm o dever de arquivar estes dados, com evidência original, para que possam acompanhar a dinâmica da ocupação do território, das edificações e das construções de muros (cercas), além de conduzir a manutenção gradativa dos dados e ainda alimentar e manter atualizada a carta cadastral, como citado na Portaria $n^{\circ} 511$ (2009) do Ministério das Cidades, em seu Art. $7^{\circ}$.

Neste sentido, devem seguir algumas etapas, como está demonstrado a seguir: 


\subsection{Rede de referência cadastral municipal}

A Rede de Referência Cadastral Municipal - RRCM (Figura 16) deve ser densificada ao nível de levantamento (Figura 15), pelo setor de cadastro das prefeituras, ou seja, deve ter uma densidade tal que cada novo ponto a ser demarcado ou medido tenha vínculo direto aos pontos da RRCM conectado ao Sistema Geodésico Brasileiro - SGB.

Experiências mostram que países com forte tradição em medição e demarcação de limites legais, como Alemanha, Suíça, e Áustria, possuem em suas áreas urbanas estruturas de pontos da RRCM com distâncias que variam de 100,00m e 150,00m entre si e demostra também como estes pontos podem ser demarcados e documentados (HASENACK, 2013).

\subsection{Identificação das parcelas}

Dentre as normas adotadas no CTM, está a identificação das parcelas. A identificação das parcelas será individualizada com código próprio. Este código deverá ser inequívoco, criado pelo setor de cadastro de forma lógica e consistente.

O setor de cadastro das prefeituras pode criar a codificação automatizada de numeração livre, fornecendo através de bancos de dados o acesso ao identificador principal - ID, sendo este o identificador da parcela. Este identificador deve ser criado pelo sistema, via WEB, visando dar maior versatilidade e agilidade, sem burocracia. Este ID gera no banco de dados um registro vazio criado para a parcela e está vinculado ao profissional credenciado no CTM, que apresentará os dados da parcela validados pelo CTM, introduzindo no ID referente. O acesso ao sistema de banco de dados deve ser livre a todos os usuários credenciados no CTM, garantindo rapidez para obter a qualquer momento os dados no sistema. 


\subsection{Codificação dos pontos}

A codificação dos pontos será de responsabilidade do profissional credenciado. Como sugestão, pode-se adotar o método indicado por Hasenack (2013) (Figura 1).

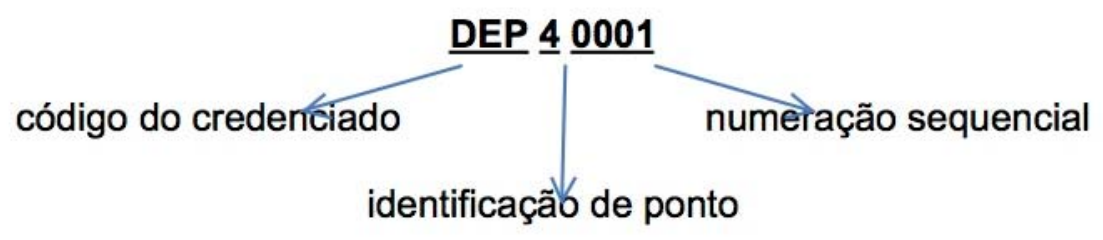

Figura 1 - Codificação dos pontos (Fonte adaptada de HASENACK, 2013)

Identificação de Ponto:

1 - para ponto de referência originado somente a partir de pontos da RRCM, demarcado;

2 - para ponto de referência, onde na sua definição são utilizados pontos mistos (tanto pontos da RRCM, como também pontos tipo 1), podendo ser demarcado ou não demarcado;

3 - para pontos auxiliares aos pontos de referência demarcados;

4 - para ponto limite legal demarcado;

5 - para ponto limite legal não demarcado;

6 - para ponto limite de edificação;

7 - para ponto de referência não demarcado. 


\subsection{Métodos de medição e demarcação}

São vários os métodos de medição e demarcação que podem ser empregados para a execução do parcelamento do solo. Dentre eles, pode-se destacar o Método Polar, o Método de Rastreio com GNSS e o Método de Alinhamento, pois permitem rapidez e confiabilidade. Estes métodos, juntamente com a forma de emprego de cada um, também devem estar comtemplados em norma técnica específica, pois deve ser garantido o princípio da vizinhança geodésica (NBR 13133/94) e a homogeneidade dos dados, com o mínimo de erro propagado, atendendo às precisões e tolerâncias definidas para este processo. Na sequência, está demonstrado o princípio de funcionamento de cada método.

\subsubsection{Método polar}

Para este método (Figura 2) deverá existir no mínimo dois pontos fixos coordenados, geometricamente vinculados à RRCM e homogêneos a ela. Instalando-se um teodolito ou taqueômetros eletrônicos (estações totais) em um destes pontos, visase a ré no outro ponto para que fique orientado ao sistema. Em seguida, visam-se os novos pontos que se deseja determinar, obtendo-se as direções e as distâncias entre o ponto em que se encontra o instrumento e os pontos que se deseja. Estes dados são anotados em um croqui, que juntamente com as medições / controle e cálculos formam os originais de levantamento cadastral de campo. 


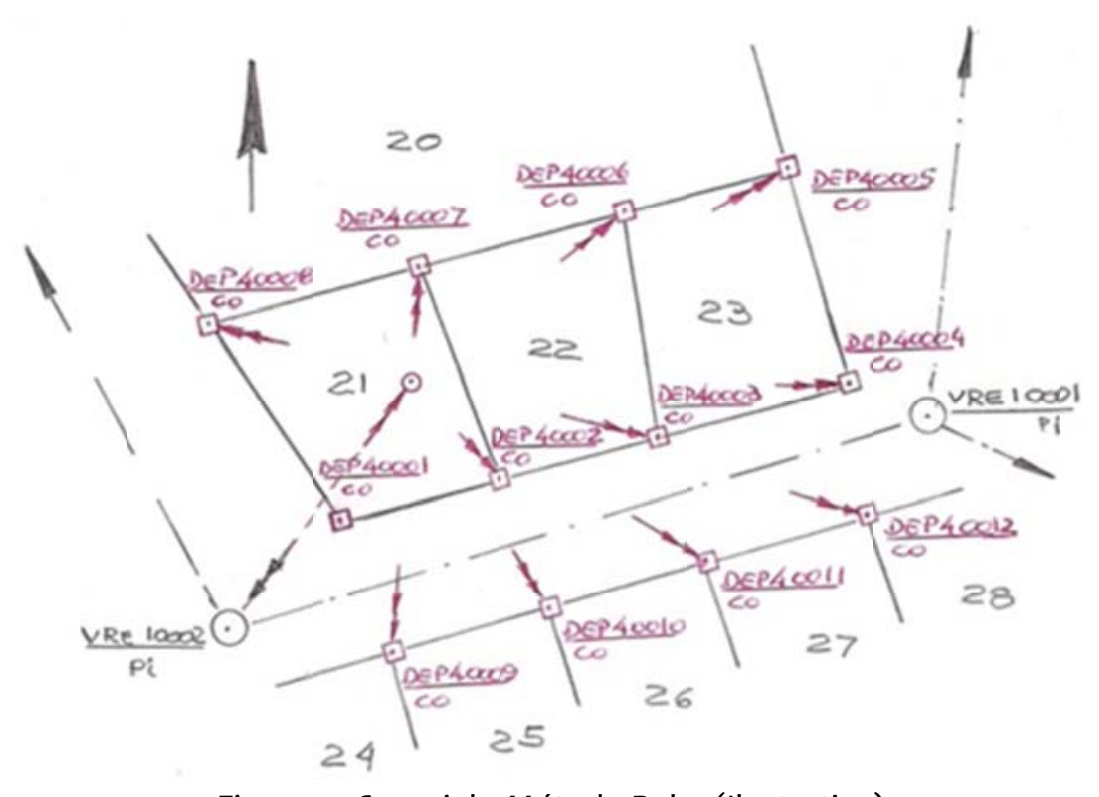

Figura 2 - Croqui do Método Polar (Ilustrativo)

\subsubsection{Método da estação livre}

Com o método da estação livre (Figura 3), inicialmente não se conhecem as coordenadas do ponto de estação (local onde será instalado o instrumento), e existe certo grau de liberdade de onde se quer estacionar o instrumento. Este grau de liberdade depende principalmente da intervisibilidade a pontos fixos de coordenadas já conhecidas (pontos de referência), bem como a novos pontos a serem determinados ou demarcados. A posição da coordenada onde o instrumento está instalado é determinada com o uso de taqueômetros eletrônicos (estações totais) visando pontos de coordenadas conhecidas. Com as coordenadas e a orientação da estação determinados, adota-se o método polar. 


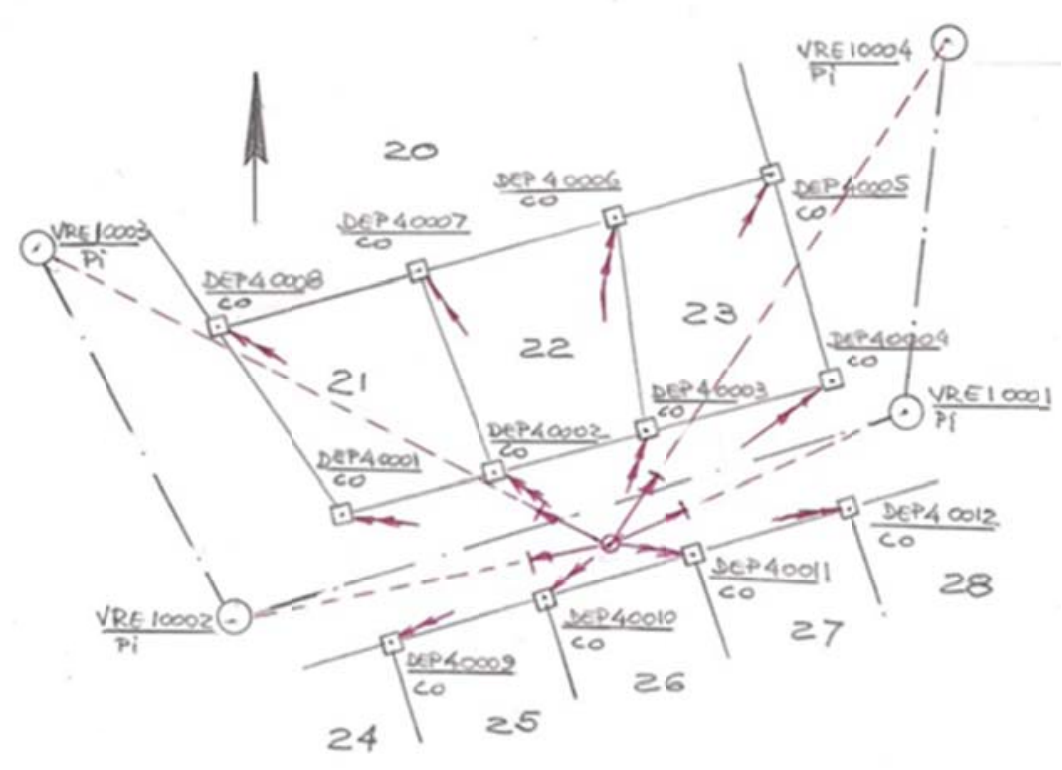

Figura 3 - Croqui do Método de Estação Livre

\subsubsection{Método GNSS com o uso da técnica RTK}

Este método (Figura 4) exige que tenhamos em campo um ponto vinculado à RRCM devidamente homogêneos a ela, onde será ocupado com um receptor, servindo de base para o processamento. O processamento é realizado em tempo real, o que significa que teremos coordenadas dos pontos medidos em campo, sabendo a sua precisão e solução encontrada. Esta técnica permite inclusive a demarcação em campo, de pontos projetados do parcelamento do solo urbano. Para o processamento em tempo real é necessário que os dados do receptor no ponto base, sejam transmitidos instantaneamente para o receptor no ponto a ser determinado. Temos como vantagem a não necessidade de intervisibilidade entre os receptores, permitindo o seu uso a até mesmos alguns quilômetros, porém tem desvantagem em áreas com obstáculos que podem provocar interrupção do sinal ou multicaminhamentos indevidos. 


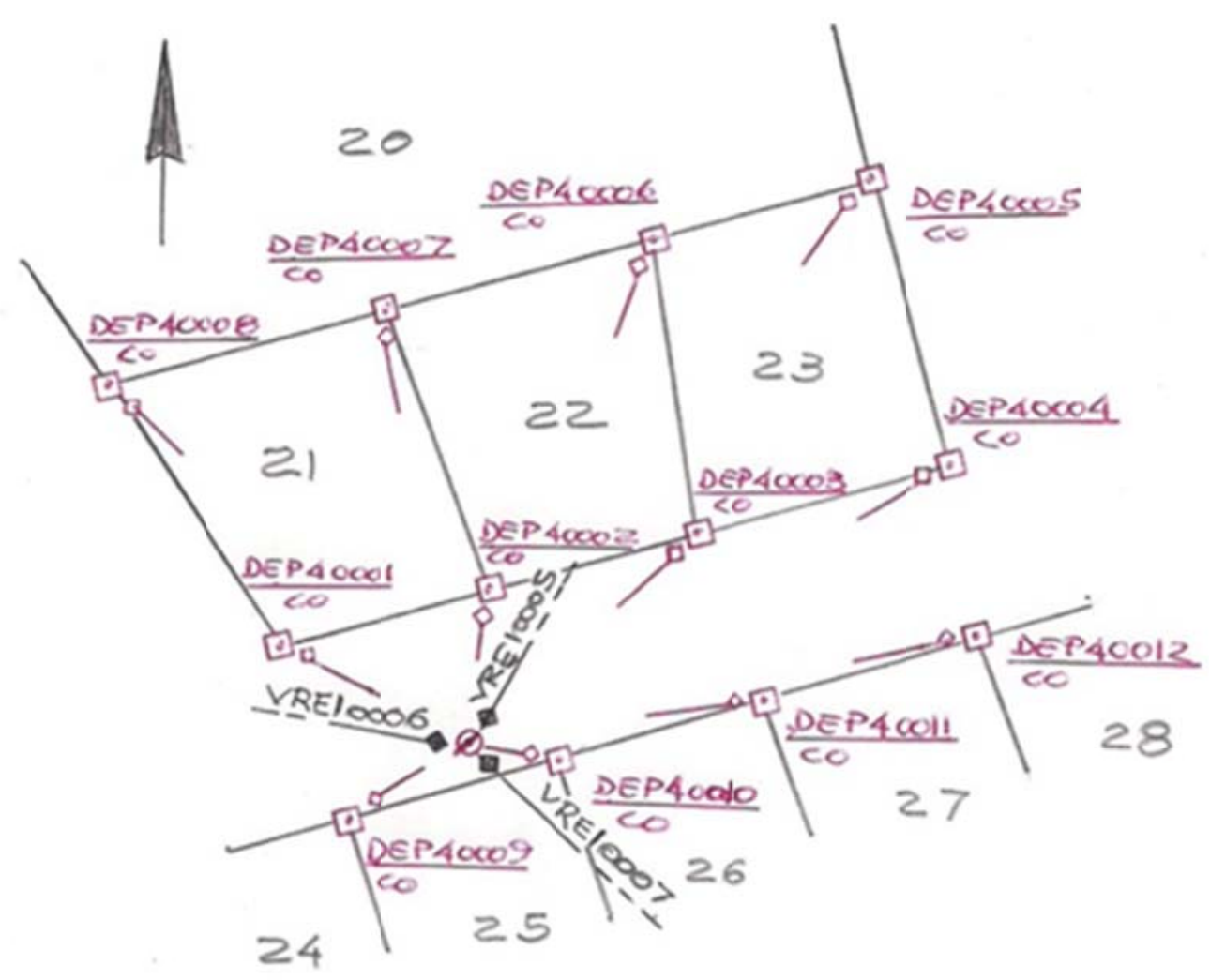

Figura 4 - Croqui do Método GNSS com o uso da técnica RTK (Ilustrativo)

\subsubsection{Método do alinhamento}

O método do alinhamento (Figura 5) necessita da existência de pontos fixos de referência monumentados no terreno e com suas coordenadas conhecidas. A posição dos objetos a serem levantados é determinada pela extensão (projeção do alinhamento) de seus elementos retos (paredes de edificações ou linhas limites de propriedades), até haver a interseção com as linhas de referência que ligam os pontos de referência ou mesmo outras linhas. Os resultados são anotados em um croqui de campo, que deverá conter todas as linhas e pontos levantados juntamente com as medições. 


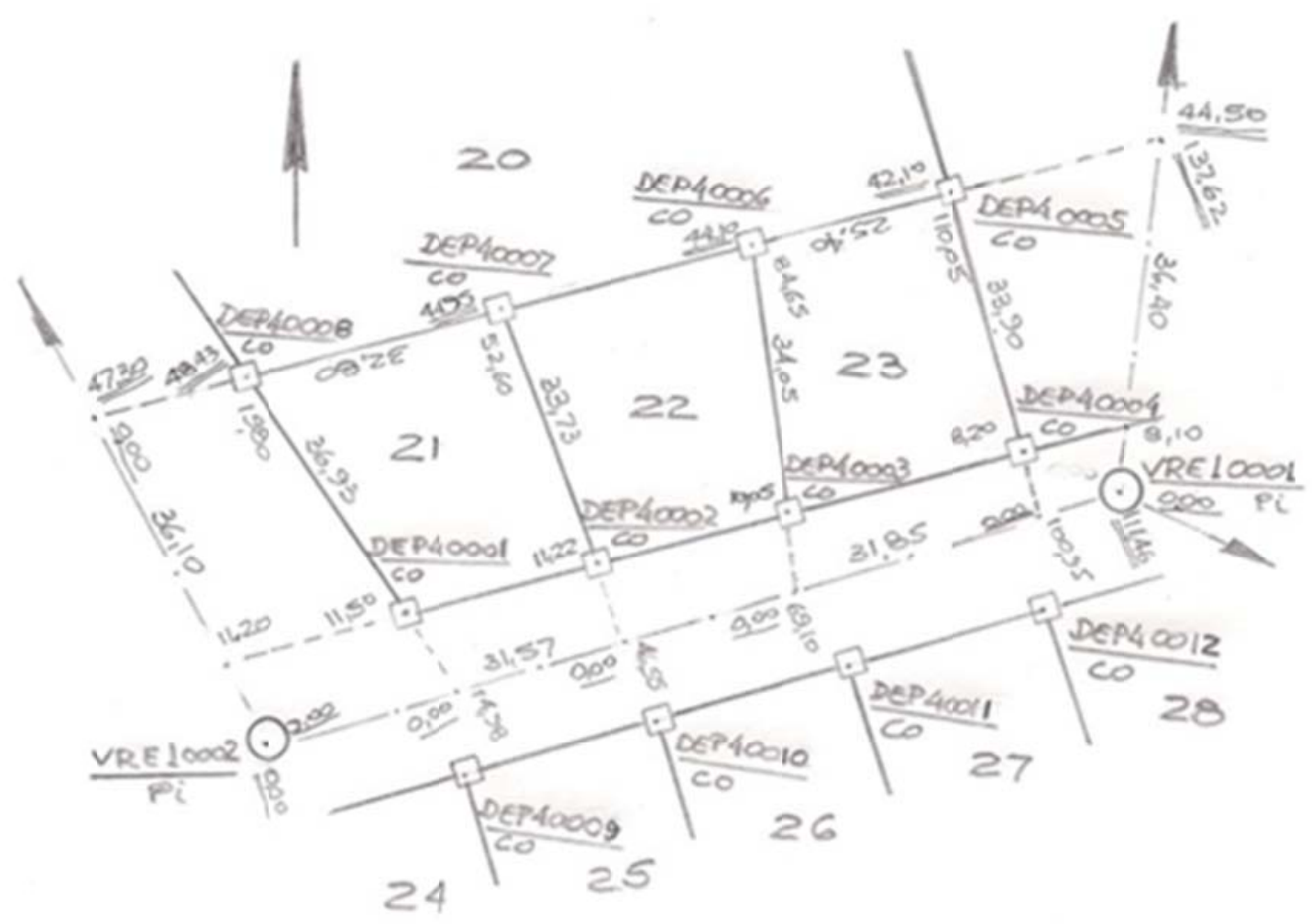

Figura 5 - Croqui do Método de Alinhamento (Ilustrativo)

\section{A gleba e o parcelamento do solo urbano}

Para se iniciar o parcelamento do solo urbano, o projeto deve ser baseado em uma gleba contendo os seus limites, confrontações e área devidamente de acordo com os dados geométricos existente no CTM e na matrícula registrada no Cartório de Registro de Imóveis. Caso contrário, deve-se adotar o procedimento previsto na Lei Federal $\mathrm{n}^{\circ}$ 10.931/2004, que alterou os Artigos 212 e 213 da Lei $n^{\circ}$ 6.015/1973, que trata do processo de retificação de área e inserção de medidas em imóvel através do procedimento administrativo.

Por exigência do setor de engenharia, através de consulta de viabilidade, o proprietário ou representante legal deverá providenciar o levantamento cadastral da gleba inserida na área urbana (Figura 6) através de profissionais agrimensores que, entende-se, devam ser credenciados junto ao setor de cadastro. 


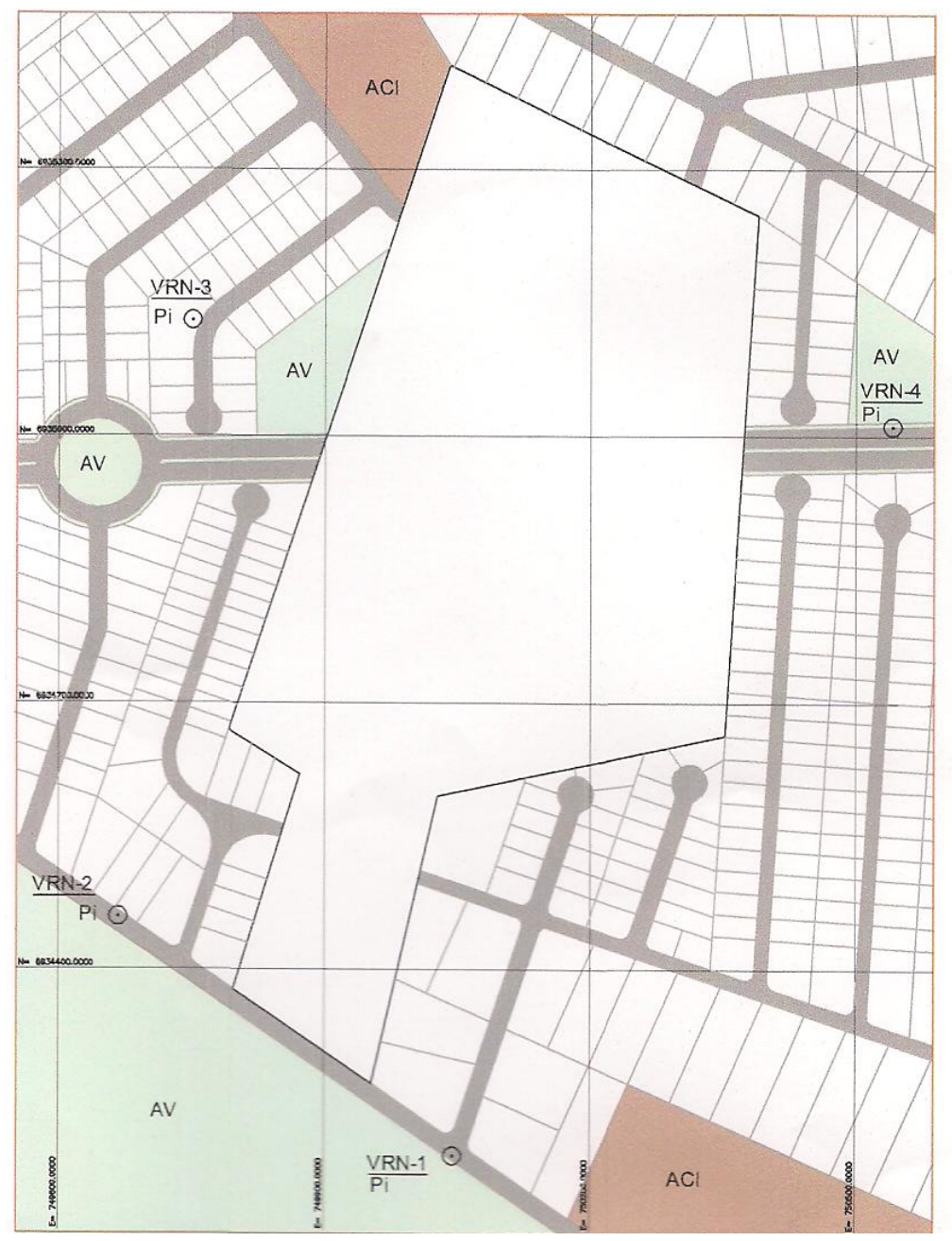

Figura 6 - Gleba inserida na área urbana

Estes profissionais credenciados deverão seguir as normas e os procedimentos do CTM. Após o levantamento cadastral, estes profissionais devem apresentar ao setor de cadastro os originais de levantamento cadastral de campo, tais como: medições e coordenadas dos pontos limites legais da gleba (Figura 7), provenientes do levantamento, relatório de medição, croquis de levantamento e de implantação cadastral da gleba (Figura 8), planta cadastral da gleba (Figura 9), e os dados que compõem os limites legais da gleba (Figura 10). 


\begin{tabular}{|l|l|l|l|l|c|}
\hline ESTAÇ̃̃O & VÉRTICES & DISTANCIA & AZIM UTE & E & N \\
\hline DEP70001 & & & & $750.088,8629$ & $6.934 .974,2970$ \\
& V RN-1 & 785,582 & $183^{\circ} 12^{\prime} 04^{\prime \prime}$ & $750.044,9954$ & $6.934 .189,9412$ \\
\hline & V RN-2 & 665,829 & $29^{\circ} 14^{\prime} 58^{\prime \prime}$ & $749.667,5938$ & $6.934 .458,6806$ \\
\hline & VRN-4 & 454,340 & $85^{\circ} 15^{\prime} 22^{\prime \prime}$ & $750.541,6467$ & $6.935 .011,8721$ \\
\hline & DEP40002 & 716,192 & $190^{\circ} 51^{\prime} 50^{\prime \prime}$ & $749.953,8776$ & $6.934 .270,9410$ \\
\hline & DEP40003 & 664,527 & $205^{\circ} 57^{\prime} 18^{\prime \prime}$ & $749.798,0231$ & $6.934 .376,7956$ \\
\hline & DEP40004 & 415,273 & $211^{\circ} 20^{\prime} 47^{\prime \prime}$ & $749.872,8333$ & $6.934 .619,6382$ \\
\hline & DEP40005 & 425,656 & $224^{\circ} 15^{\prime} 37^{\prime \prime}$ & $749.791,7890$ & $6.934 .669,4527$ \\
\hline & DEP40006 & 444,930 & $353^{\circ} 50^{\prime} 41^{\prime \prime}$ & $750.041,1561$ & $6.935 .416,6621$ \\
\hline & DEP40007 & 407,499 & $47^{\circ} 42^{\prime} 06^{\prime \prime}$ & $750.390,2701$ & $6.935 .248,5400$ \\
\hline & DEP40008 & 407,998 & $139^{\circ} 40^{\prime} 45^{\prime \prime}$ & $750.352,8650$ & $6.934 .663,2259$ \\
\hline & DEP40009 & 384,306 & $1^{\circ} 09^{\circ} 00^{\prime} 31^{\prime \prime}$ & $750.028,6877$ & $6.934 .594,7317$ \\
\hline
\end{tabular}

Figura 7 - Medições e coordenadas dos pontos limites legais da gleba

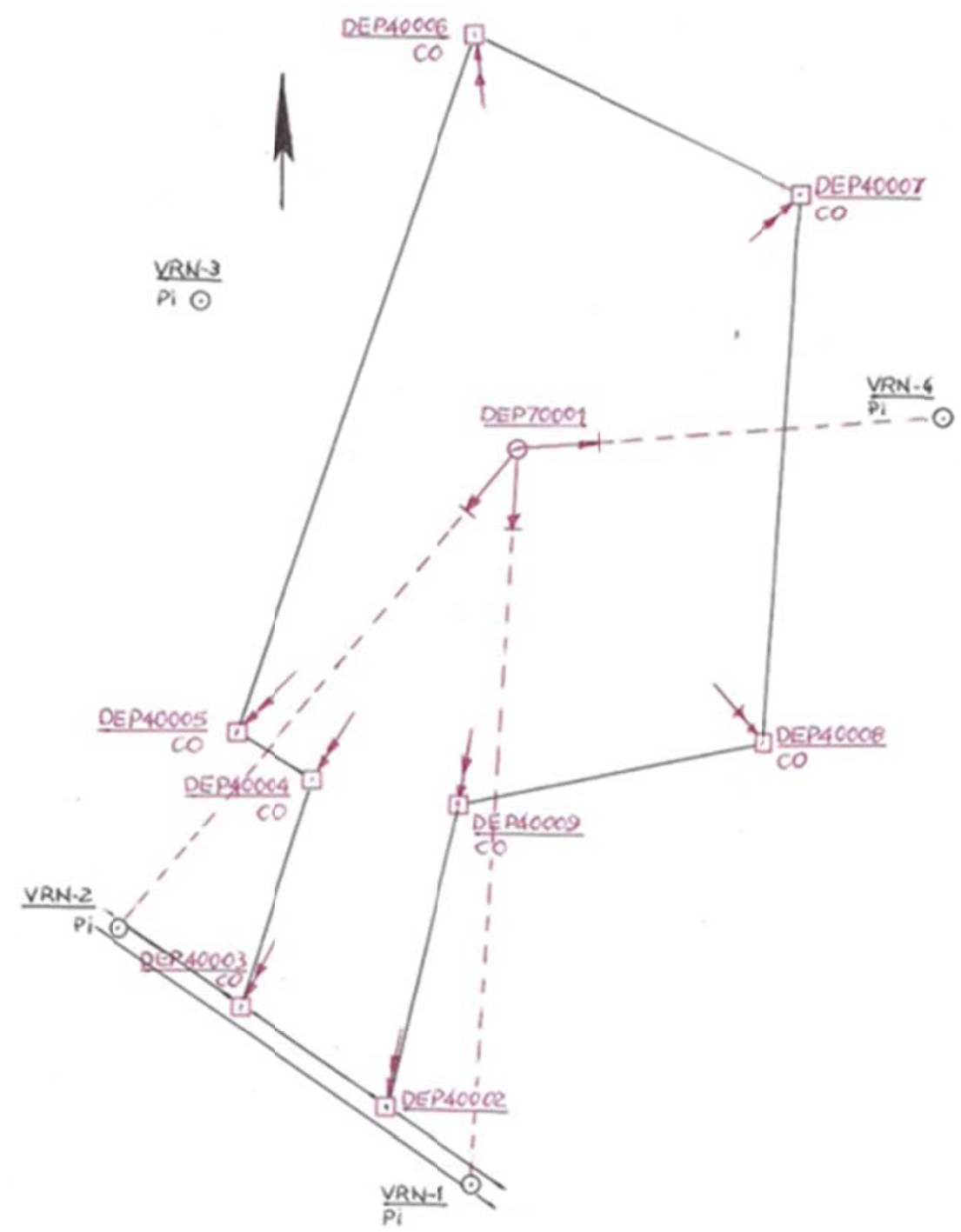

Figura 8 - Croqui de levantamento e implantação cadastral da gleba 


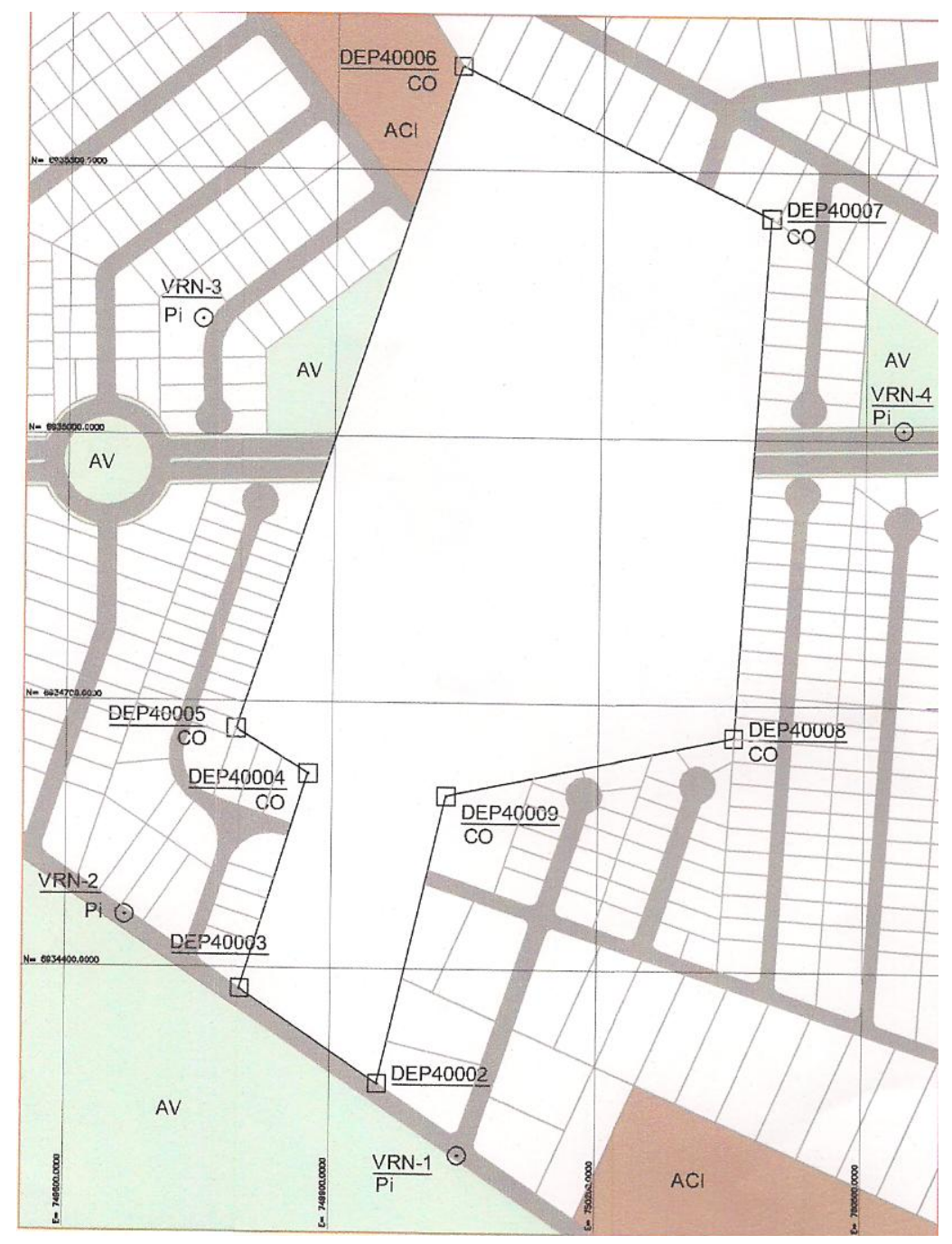

Figura 9 - Planta cadastral da gleba

\begin{tabular}{|c|c|c|c|c|c|c|c|}
\hline \multicolumn{2}{|c|}{ LIMITE LEGAL DA GLEBA } & \multirow[b]{2}{*}{ DISTANCIA } & \multirow[b]{2}{*}{ ANG.INTERNO } & \multirow[b]{2}{*}{ AZIMUTE } & \multirow[b]{2}{*}{ RUMO Q } & \multirow[b]{2}{*}{$\mathrm{E}$} & \multirow[b]{2}{*}{$\mathrm{N}$} \\
\hline PONTO & ALINHAMENTO & & & & & & \\
\hline DEP40002 & DEP40002-DEP40003 & 188,403 & $68^{\circ} 49^{\prime} 32^{\prime \prime}$ & $304^{\prime} 11^{\prime} 02^{\prime \prime}$ & $55^{\circ} 48^{\prime} 58^{\prime \prime} \mathrm{NO}$ & $749.953,8776$ & $6.934 .270,9410$ \\
\hline DEP40003 & DEP40003-DEP40004 & 254,105 & $107^{\circ} 03^{\prime} 43^{\prime \prime}$ & $17^{\circ} 07^{\prime} 19^{\prime \prime}$ & $17^{\circ} 07^{\prime} 19^{\prime \prime} \mathrm{NE}$ & $749.798,0231$ & $6.934 .376,7956$ \\
\hline DEP40004 & DEP40004-DEP40005 & 95,129 & $255^{\circ} 32^{\prime} 42^{\prime \prime}$ & $301^{\circ} 34^{\prime} 37^{\prime \prime}$ & $58^{\circ} 25^{\prime} 23^{\prime \prime} \mathrm{NO}$ & $749.872,8333$ & $6.934 .619,6382$ \\
\hline DEP40005 & DEP40005-DEP40006 & 787,722 & $103^{\circ} 07^{\prime} 18^{\prime \prime}$ & $18^{\circ} 2720^{\prime \prime}$ & $18^{\circ} 27^{\prime} 20^{\prime \prime} \mathrm{NE}$ & $749.791,7890$ & $6.934 .669,4527$ \\
\hline DEP40006 & DEP40006-DEP40007 & 387,486 & $82^{\circ} 44^{\prime} 29^{\prime \prime}$ & $115^{\circ} 42^{\prime} 50^{\prime \prime}$ & $64^{\circ} 17^{\prime} 10^{\prime \prime} \mathrm{SE}$ & $750.041,1561$ & $6.935 .416,6621$ \\
\hline DEP40007 & DEP40007-DEP40008 & 586,508 & $112^{\circ} 03^{\prime} 2 \mathrm{~T}$ & 183'39'24" & $3^{\circ} 39^{\prime} 24^{\prime \prime} \mathrm{SO}$ & $750.390,2701$ & $6.935 .248,5400$ \\
\hline DEP40008 & DEP40008-DEP40009 & 331,334 & $105^{\circ} 35^{\prime} 13^{\prime \prime}$ & $258^{\circ} 04^{\prime} 11^{\prime \prime}$ & $78^{\circ} 04^{\prime} 11^{\prime \prime}$ SO & $750.352,8650$ & $6.934 .663,2259$ \\
\hline DEP40009 & DEP40009-DEP40002 & 332,321 & $245^{\circ} 03^{\prime} 36^{\prime \prime}$ & $193^{\circ} 00^{\prime} 35^{\prime \prime}$ & $13^{\prime} 00^{\prime} 35^{\prime \prime} \mathrm{SO}$ & $750.028,6877$ & $6.934 .594,7317$ \\
\hline \multirow{2}{*}{\multicolumn{2}{|c|}{ ÁREA $=387856.44 \mathrm{~m} 2$}} & & & & & & \\
\hline & $\mathrm{O}=2963.009 \mathrm{~m}$ & & & & & & \\
\hline
\end{tabular}

Figura 10 - Dados dos limites legais da gleba

Após a análise destes documentos pelo setor de cadastro é que serão certificadas as coordenadas dos pontos limites legais da gleba, que serão enviadas ao proprietário, para que este providencie, junto ao Registro de Imóveis, a retificação e atualização da 
matrícula da gleba. Todo esse procedimento é demonstrado no "Fluxograma para a certificação das coordenadas e a necessidade de retificação da matrícula da gleba" (Figura 11).

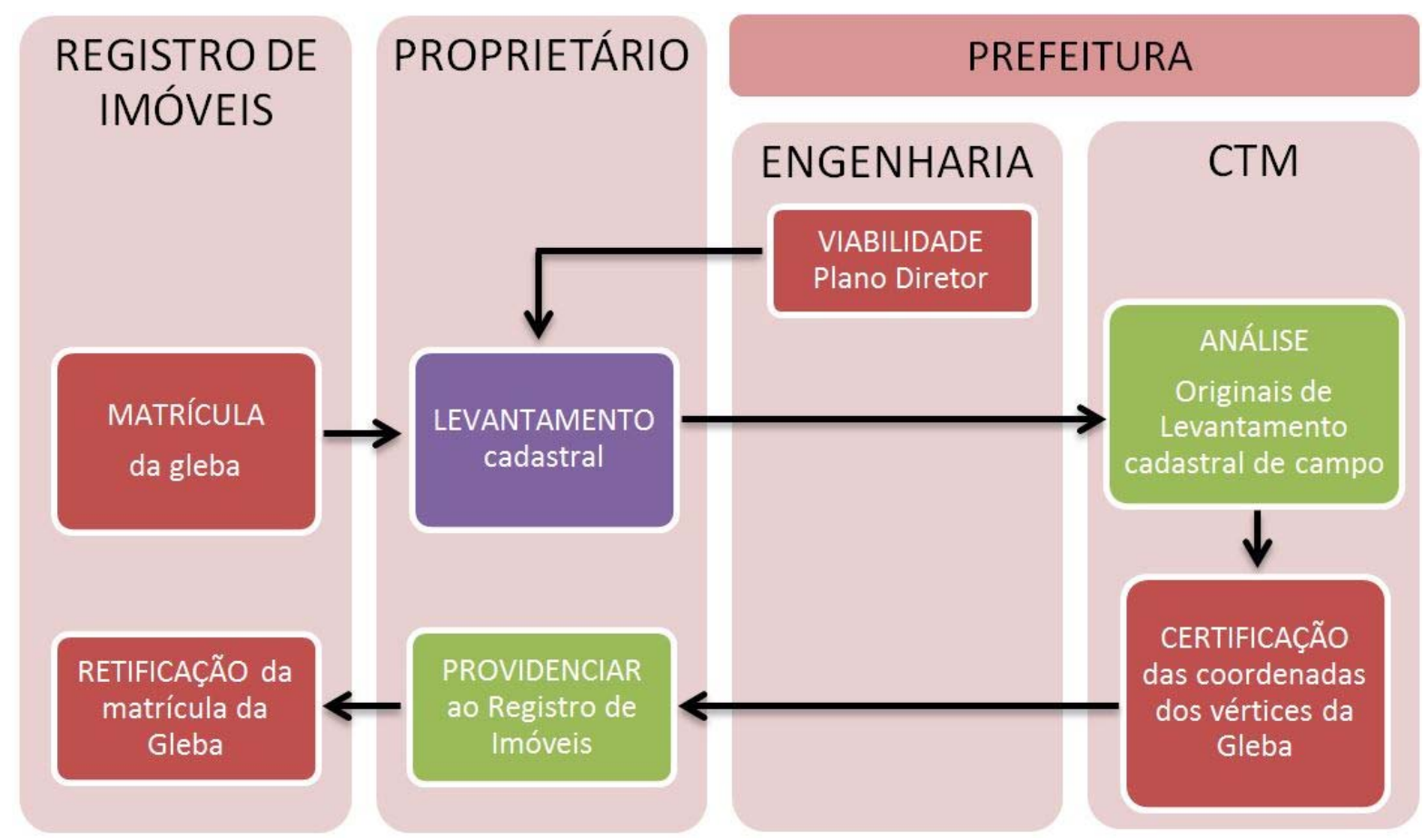

Figura 11 - Fluxograma para a certificação das coordenadas e a necessidade de retificação da matrícula da gleba

\section{Projeto de parcelamento do solo urbano para atender ao sistema básico do CTM}

A Lei Federal n6.766/1979, que dispõe sobre o parcelamento do solo urbano e dá outras providências, é também seguida por outras leis pertinentes, tanto no âmbito estadual quanto no municipal. Existem leis complementares a esta, sendo sempre mais rigorosas nas exigências do parcelamento do solo urbano. Estas leis ordenam o parcelamento territorial na definição de diretrizes para o uso e ocupação do solo, como as dimensões das parcelas, sistemas viários, espaços livres, áreas verdes, áreas comunitárias, etc... 
Este processo tem início em uma consulta de viabilidade que é o procedimento que o proprietário, ou representante legal do imóvel deve fazer ao setor de engenharia da prefeitura, para que esta informe oficialmente as necessidades e restrições de acordo com as legislações do Plano Diretor e do Parcelamento do Solo Urbano.

Para a execução do projeto de parcelamento do solo urbano, deve ser condição que a gleba esteja atualizada no CTM.

Com o resultado da viabilidade e de posse dos dados cadastrais da gleba fornecido pelo CTM, o proprietário terá a garantia de poder realizar seu empreendimento com segurança, e posteriormente a sua execução.

O passo seguinte é a elaboração do projeto de parcelamento do solo urbano, conforme a viabilidade, juntamente com os dados geodésicos que definem o polígono da gleba, fornecidos pelo CTM, e a legislação do parcelamento do solo urbano.

Este projeto de parcelamento do solo urbano, realizado por profissionais habilitados, será encaminhado à prefeitura, onde deve ser analisado pelo setor de engenharia. Depois de aprovado o projeto, este deve seguir para o CTM para que seja cadastrado no sistema. A figura 12 apresenta o projeto aprovado com os pontos limites legais da gleba e a localização dos pontos da RRCM em seu entorno. 


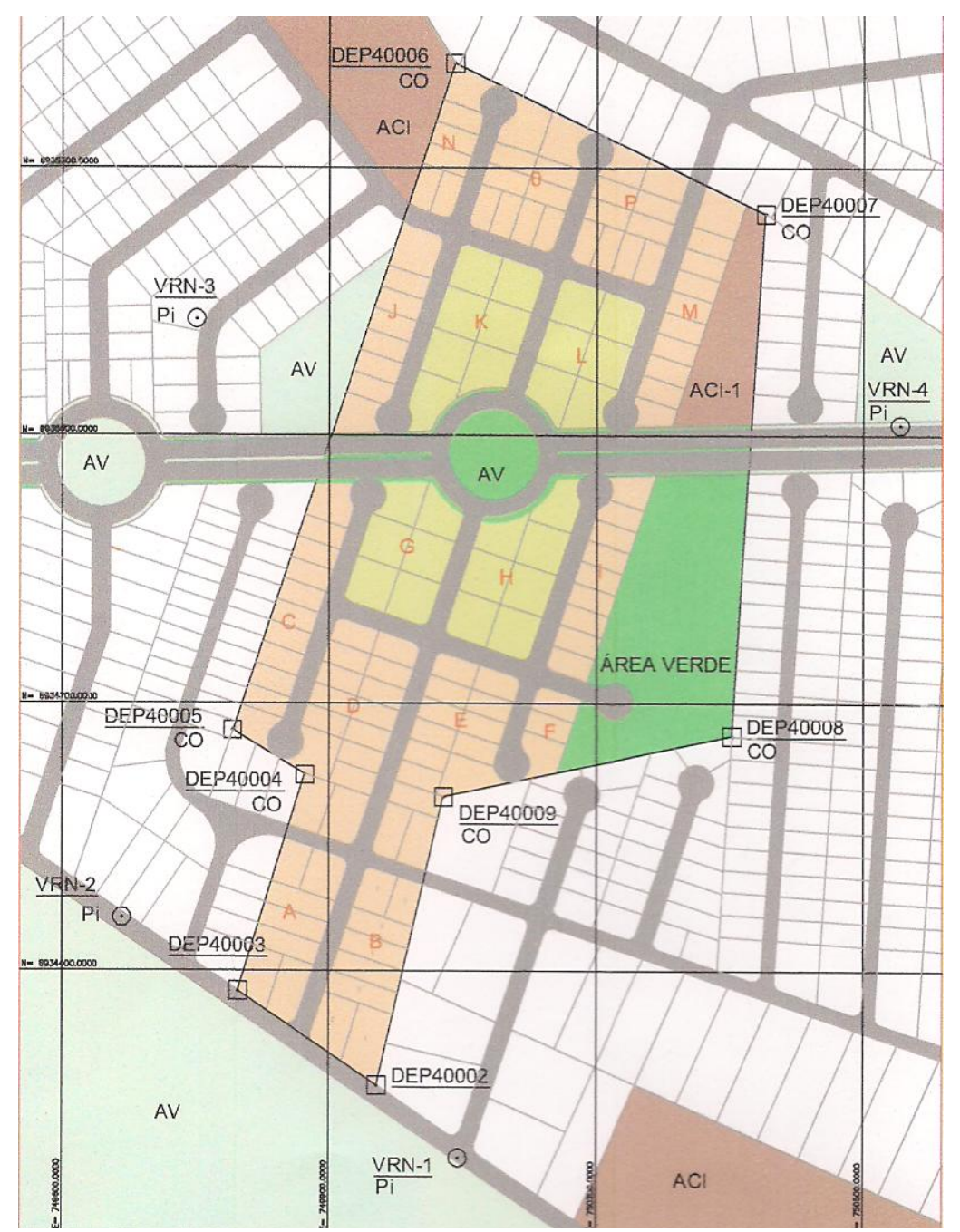

Figura 12 - Projeto aprovado com os pontos limites legais da gleba e a localização dos pontos da RRCM em seu entorno

Para a implantação do parcelamento do solo urbano, o profissional habilitado e credenciado deverá obter os originais de levantamento cadastral de campo da gleba, com o extrato que contém: o polígono da gleba, a lista de coordenadas dos pontos limites legais da gleba, (Figura 13), localização dos pontos da RRCM (Figura 14), e a lista de coordenadas da RRCM (Figura 15). Como exemplo, apresentamos a planta da quadra "B" (Figura 16) e a lista de coordenadas dos pontos limites legais das parcelas do parcelamento do solo urbano projetado (Figura 17), todos provenientes dos arquivos do CTM.

De posse destes dados é que o profissional credenciado vai a campo fazer a implantação das parcelas do parcelamento do solo urbano. 


\begin{tabular}{|l|l|l|}
\hline \multirow{2}{*}{ PONTO } & E & $\mathrm{N}$ \\
\hline DEP40002 & $749.953,8776$ & $6.934 .270,9410$ \\
\hline DEP40003 & $749.798,0231$ & $6.934 .376,7956$ \\
\hline DEP40004 & $749.872,8333$ & $6.934 .619,6382$ \\
\hline DEP40005 & $749.791,7890$ & $6.934 .669,4522$ \\
\hline DEP40006 & $750.041,1561$ & $6.935 .416,6621$ \\
\hline DEP40007 & $750.390,2701$ & $6.935 .248,5400$ \\
\hline DEP40008 & $750.352,8650$ & $6.934 .663,2259$ \\
\hline DEP40009 & $750.028,6877$ & $6.934 .594,7317$ \\
\hline
\end{tabular}

Figura 13 - Lista de coordenadas dos pontos limites legais da gleba

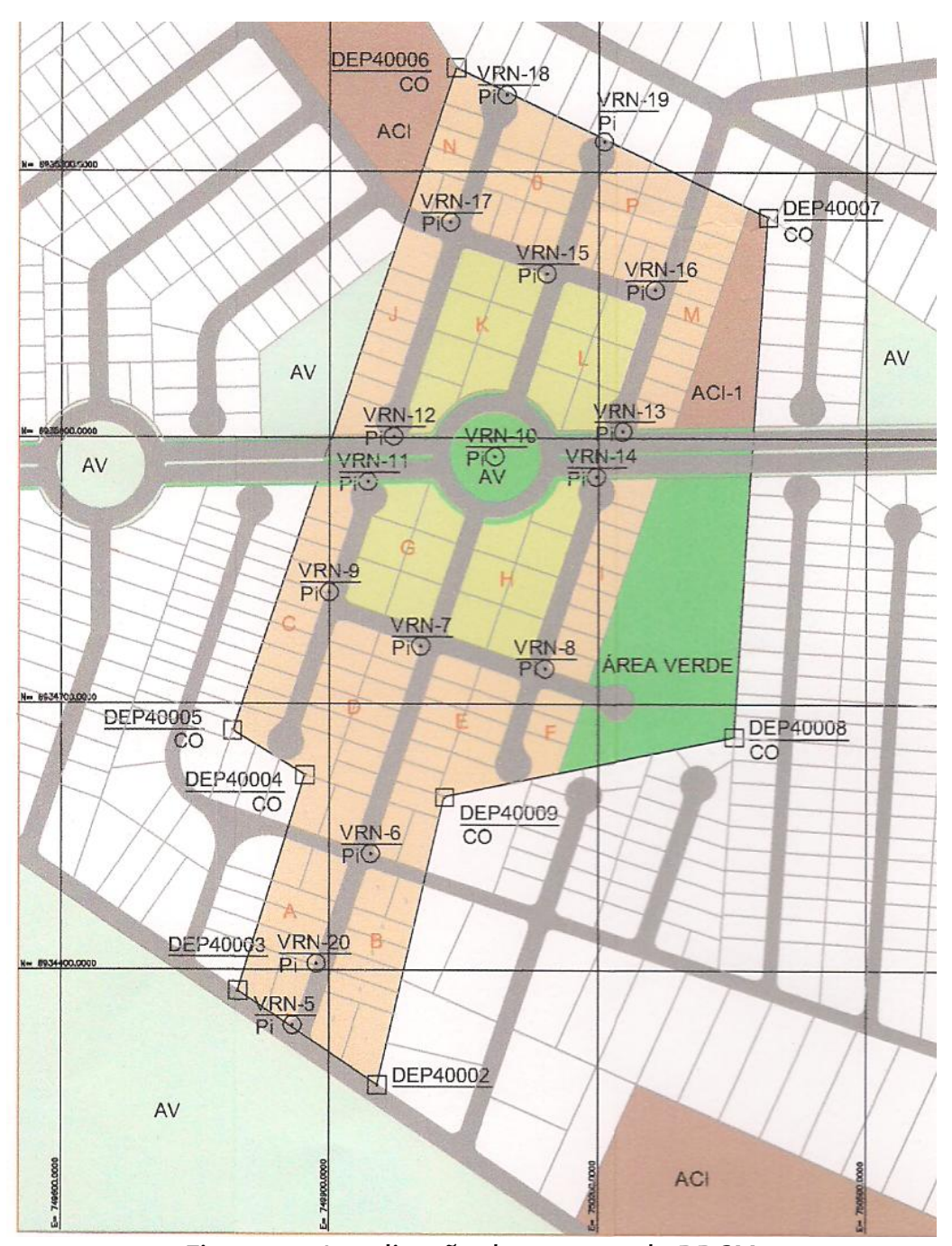

Figura 14 - Localização dos pontos da RRCM 


\begin{tabular}{|l|c|c|}
\hline \multicolumn{3}{|c|}{ COORDENADAS DA RRCM } \\
\hline PONTO & $\mathrm{E}$ & $\mathrm{N}$ \\
\hline VRN-1 & $750.044,9954$ & $6.934 .189,9412$ \\
\hline VRN-2 & $749.667,5938$ & $6.934 .458,6806$ \\
\hline VRN-3 & $749.750,5125$ & $6.935 .129,9790$ \\
\hline VRN-4 & $750.541,6467$ & $6.935 .011,8721$ \\
\hline VRN -5 & $749.858,9931$ & $6.934 .338,0919$ \\
\hline VRN-6 & $749.946,0843$ & $6.934 .531,1823$ \\
\hline VRN-7 & $750.002,3407$ & $6.934 .765,0541$ \\
\hline VRN-8 & $750.140,7626$ & $6.934 .740,0337$ \\
\hline VRN-9 & $749.899,5575$ & $6.934 .825,5752$ \\
\hline VRN-10 & $750.084,8300$ & $6.934 .978,9283$ \\
\hline VRN-11 & $749.942,6829$ & $6.934 .950,2973$ \\
\hline VRN-12 & $749.971,4404$ & $6.935 .001,5938$ \\
\hline VRN-13 & $750.228,4659$ & $6.935 .007,3307$ \\
\hline VRN-14 & $750.197,7046$ & $6.934 .956,4183$ \\
\hline VRN-15 & $750.142,3771$ & $6.935 .184,4708$ \\
\hline VRN-16 & $750.264,2599$ & $6.935 .166,2390$ \\
\hline VRN-17 & $750.034,6912$ & $6.935 .242,6482$ \\
\hline VRN-18 & $750.098,0565$ & $6.935 .386,1479$ \\
\hline VRN-19 & $750.098,0565$ & $6.935 .386,1479$ \\
\hline VRN-20 & $749.885,7197$ & $6.934 .407,5044$ \\
\hline
\end{tabular}

Figura 15 - Coordenadas dos pontos da RRCM

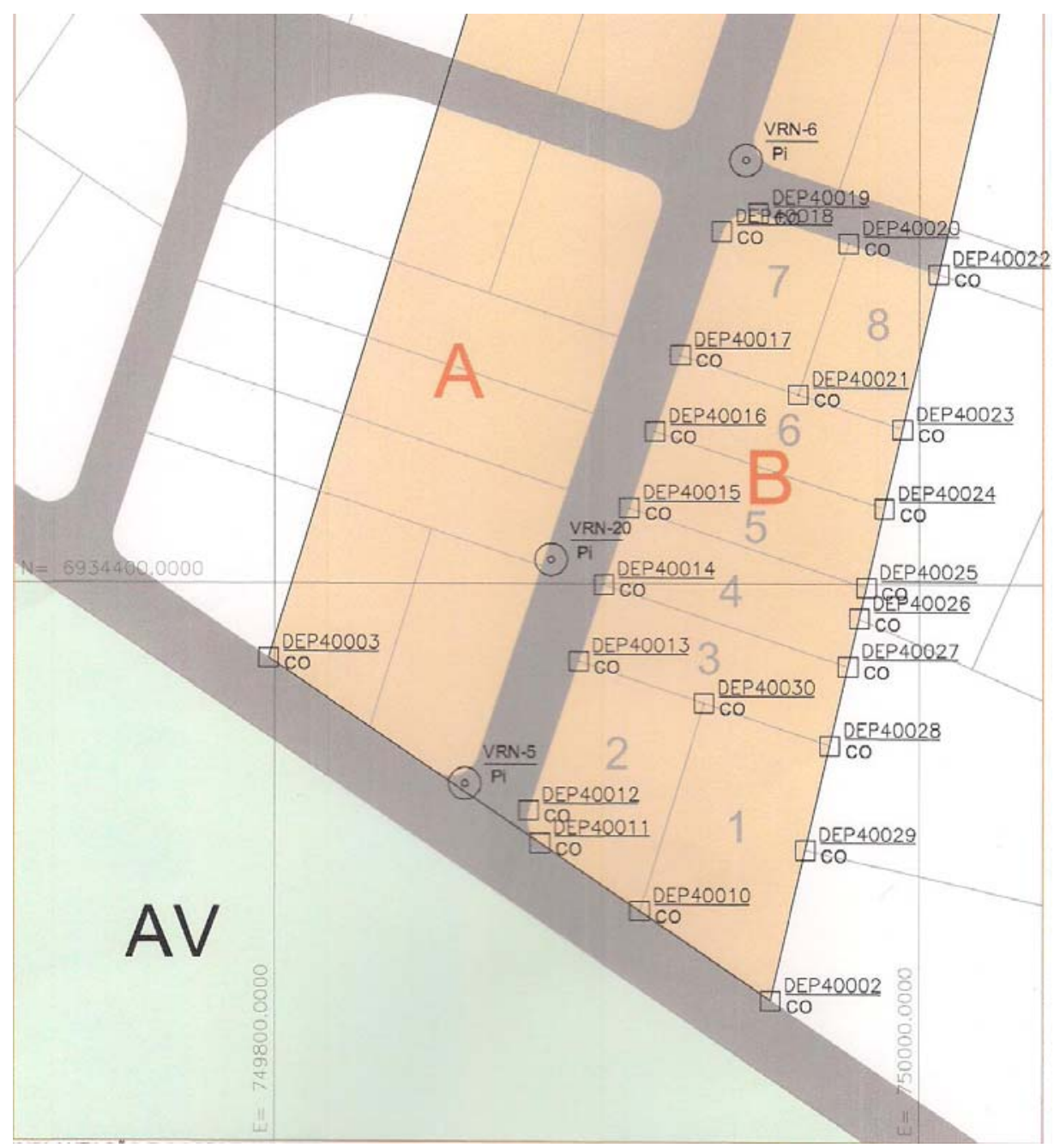

Figura 16 - Planta da quadra "B" 


\begin{tabular}{|l|c|c|}
\hline \multirow{2}{*}{ PONTO } & \multicolumn{2}{|c|}{ COORDENADAS } \\
\cline { 2 - 3 } & $\mathrm{E}$ & $\mathrm{N}$ \\
\hline DEP40010 & $749.913,2831$ & $6.934 .298,5123$ \\
\hline DEP40011 & $749.882,2469$ & $6.934 .319,5917$ \\
\hline DEP40012 & $749.878,7665$ & $6.934 .329,8860$ \\
\hline DEP40013 & $749.894,1785$ & $6.934 .376,0670$ \\
\hline DEP40014 & $749.902,0927$ & $6.934 .399,7813$ \\
\hline DEP40015 & $749.910,0069$ & $6.934 .423,4955$ \\
\hline DEP40016 & $749.917,9211$ & $6.934 .447,2098$ \\
\hline DEP40017 & $749.925,8353$ & $6.934 .470,9240$ \\
\hline DEP40018 & $749.938,5890$ & $6.934 .509,1396$ \\
\hline DEP40019 & $749.949,9752$ & $6.934 .514,8276$ \\
\hline DEP40020 & $749.977,9442$ & $6.934 .505,4935$ \\
\hline DEP40021 & $749.962,3413$ & $6.934 .458,7408$ \\
\hline DEP40022 & $750.005,9131$ & $6.934 .496,1594$ \\
\hline DEP40023 & $749.994,7675$ & $6.934 .447,9192$ \\
\hline DEP40024 & $749.989,1141$ & $6.934 .423,4504$ \\
\hline DEP40025 & $749.983,4607$ & $6.934 .398,9817$ \\
\hline DEP40026 & $749.981,2370$ & $6.934 .389,3570$ \\
\hline DEP40027 & $749.977,8074$ & $6.934 .374,5129$ \\
\hline DEP40028 & $749.972,1540$ & $6.934 .350,0442$ \\
\hline DEP40029 & $749.964,6580$ & $6.934 .317,6002$ \\
\hline DEP40030 & $749.933,1662$ & $6.934 .363,0556$ \\
\hline a & \\
\hline
\end{tabular}

Figura 17 - Lista de coordenadas dos pontos limites legais das parcelas da quadra "B"

Em campo e de acordo com as normas e procedimentos definidos pelo setor de cadastro, cada ponto limite legal da parcela projetada é implantado. Na figura 18 e 19, podemos observar os pontos limites legais das parcelas demarcados com marcos de concreto.

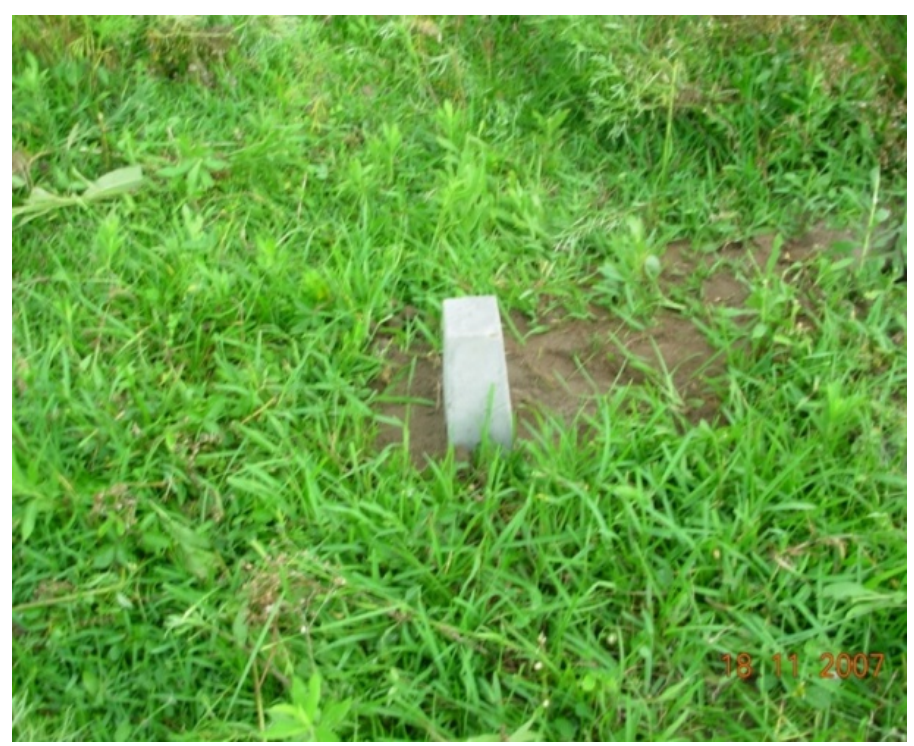

Figura 18 - Marco de concreto dos pontos limites legais das parcelas 12-08-2013 (Fonte: o autor) 


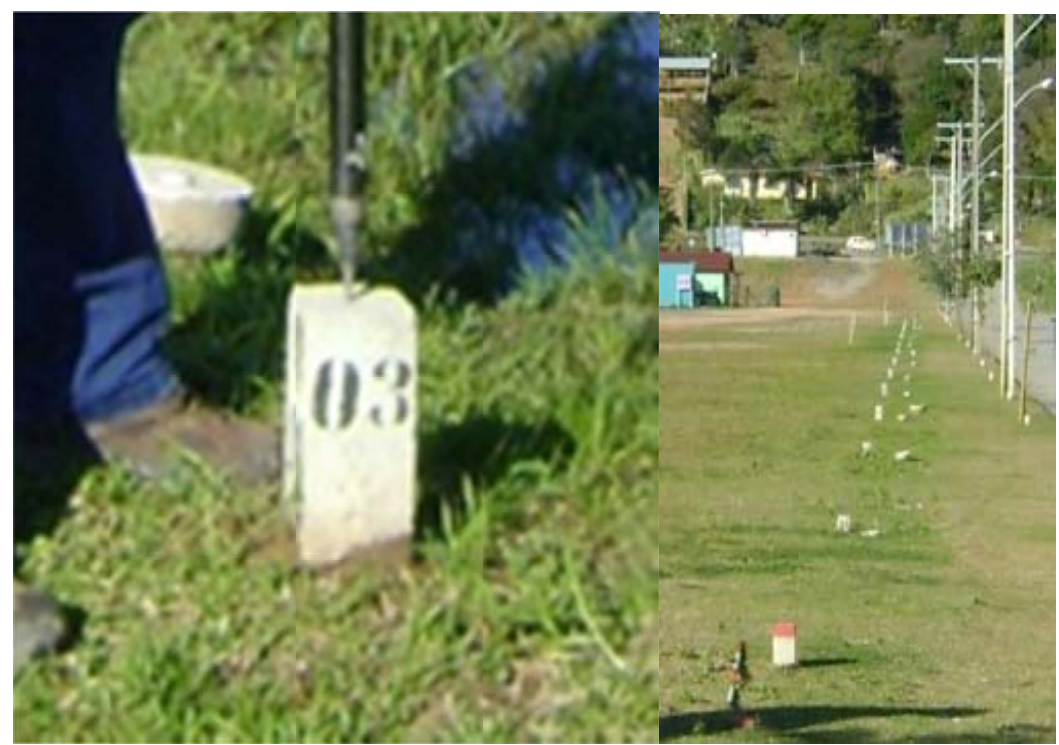

Figura 19 - Marco de concreto dos pontos limites legais das parcelas 12-08-2013 (Fonte: o autor)

Uma vez implantado o parcelamento do solo urbano, o profissional habilitado e credenciado deve realizar o como construído (as built ABNT - NBR 14645-3), em que a tolerância geométrica dos pontos limites das parcelas não deve ser superior a \0,10m.

Deverão ser apresentados ao setor de cadastro os originais de levantamento cadastral de campo, tais como: croqui das medições e controles das parcelas implantadas (Figura 20), dados das medições de implantação das parcelas (Figura 21) e dados das medições de controles das parcelas (Figura 22) para a análise e posterior certificação das coordenadas dos pontos limites legais das parcelas implantadas.

Esta deve ser a condição para que os dados possam ser certificados no sistema, somente assim é que o parcelamento do solo urbano será aprovado pelo setor de engenharia da prefeitura. De posse dessa aprovação o proprietário proviidencia junto ao $\mathrm{RI}$ as matrículas das referidas parcelas. Esse procedimento é demonstrado através do “Fluxograma para o cadastro do parcelamento do solo urbano" (Figura 23). 


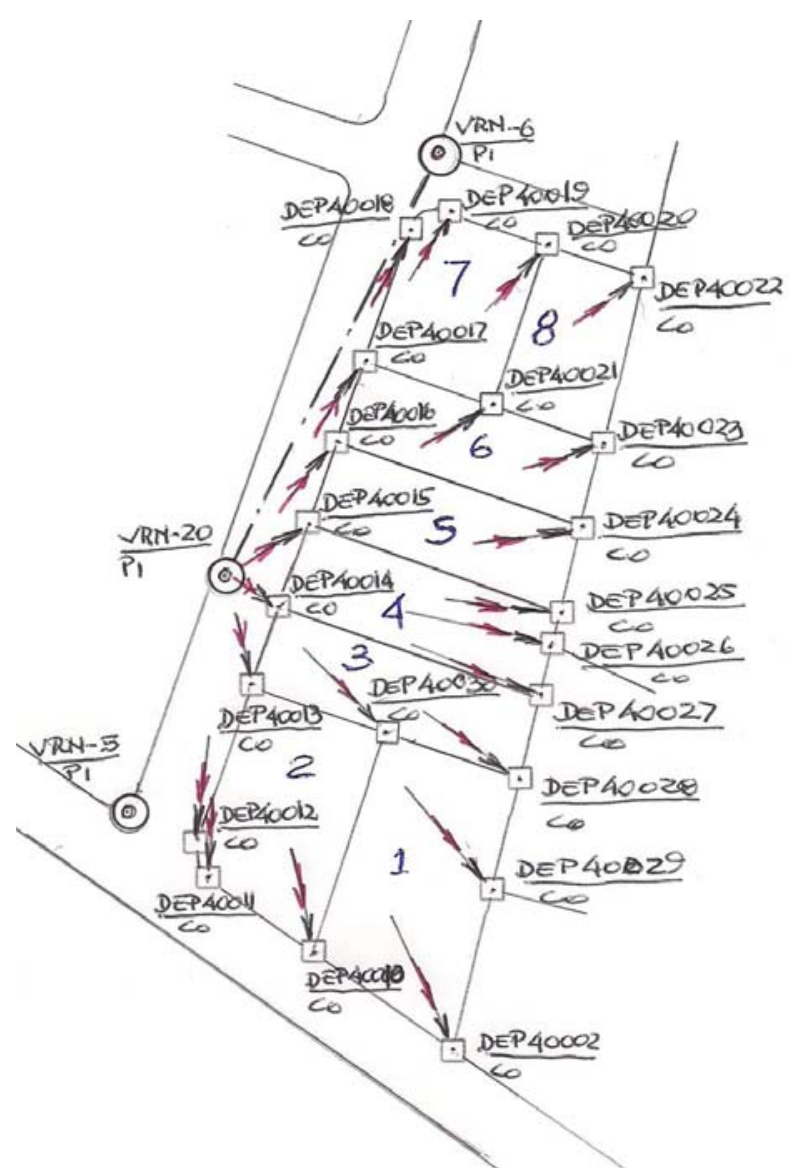

Figura 20 - Croqui de medição e controle das parcelas implantadas

\begin{tabular}{|c|c|c|c|c|c|}
\hline ESTAÇÃ̃O & PONTO & DISTANCIA & AZIMUTE & $\mathrm{E}$ & $\mathrm{N}$ \\
\hline \multirow{23}{*}{ VRN -20} & & & & $749.885,7197$ & $6.934 .407,5044$ \\
\hline & VRN-6 & 137,623 & $26^{\prime} 00^{\prime} 58^{\prime \prime}$ & $749.946,0843$ & $6.934 .531,1823$ \\
\hline & DEP40010 & 112,423 & $165^{\prime} 48^{\prime} 28^{\prime \prime}$ & $749.913,2831$ & $6.934 .298,5123$ \\
\hline & DEP40011 & 87,981 & $182315^{\prime} 44^{\prime \prime}$ & $749.882,2469$ & $6.934 .319,5917$ \\
\hline & DEP40012 & 77,929 & $185307^{\prime} 08^{\prime \prime}$ & $749.878,7665$ & $6.934 .329,8860$ \\
\hline & DEP40013 & 32,555 & 164 "56'24" & $749.894,1785$ & $6.934 .376,0670$ \\
\hline & DEP40014 & 18,103 & $115^{\prime} 15^{\prime} 11^{\prime \prime}$ & $749.902,0927$ & $6.934 .399,7813$ \\
\hline & DE P40015 & 29,079 & $56^{\prime} 38^{\prime} 18^{\prime \prime}$ & $749.910,0069$ & $6.934 .423,4955$ \\
\hline & DEP40016 & 51,122 & $39302^{\prime} 33^{\prime \prime}$ & $749.917,9211$ & $6.934 .447,2098$ \\
\hline & DEP40017 & 75,042 & $32318^{\prime} 54^{\prime \prime}$ & $749.925,8353$ & $6.934 .470,9240$ \\
\hline & DEP40018 & 114,564 & $27^{\circ} 28^{\prime} 58^{\prime \prime}$ & $749.938,5890$ & $6.934 .509,1396$ \\
\hline & DEP40019 & 125,088 & $30^{\circ} 54^{\prime} 34^{\prime}$ & $749.949,9752$ & $6.934 .514,8276$ \\
\hline & DEP40020 & 134,563 & $43^{\circ} 15^{\prime} 15^{\prime \prime}$ & $749.977,9442$ & $6.934 .505,4935$ \\
\hline & DEP40021 & 92,174 & $56^{\circ} 13^{\prime} 47^{\prime \prime}$ & $749.962,3413$ & $6.934 .458,7408$ \\
\hline & DEP40022 & 149,353 & $53^{\circ} 35^{\prime} 15^{\prime \prime}$ & $750.005,9131$ & $6.934 .496,1594$ \\
\hline & DEP40023 & 116,296 & $69^{\circ} 39^{\prime} 52^{\prime \prime}$ & $749.994,7675$ & $6.934 .447,9192$ \\
\hline & DEP40024 & 104,617 & $81^{\circ} 13^{\prime} 57^{\prime \prime}$ & $749.989,1141$ & $6.934 .423,4504$ \\
\hline & DEP40025 & 98,112 & $94^{\prime} 59^{\prime} 00^{\prime \prime}$ & $749.983,4607$ & $6.934 .398,9817$ \\
\hline & DEP40026 & 97,226 & $100^{\circ} 45^{\prime} 27^{\prime \prime}$ & $749.981,2370$ & $6.934 .389,3570$ \\
\hline & DEP40027 & 97,819 & $109^{\circ} 42^{\prime} 38^{\prime \prime}$ & $749.977,8074$ & $6.934 .374,5129$ \\
\hline & DEP40028 & 103,791 & $123^{\circ} 36^{\prime} 55^{\prime \prime}$ & $749.972,1540$ & $6.934 .350,0442$ \\
\hline & DEP40029 & 119,641 & $138^{\circ} 42^{\prime} 58^{\prime \prime}$ & $749.964,6580$ & $6.934 .317,6002$ \\
\hline & DEP40030 & 65,014 & $133^{\circ} 07^{\prime} 54^{\prime \prime}$ & $749.933,1662$ & $6.934 .363,0556$ \\
\hline
\end{tabular}

Figura 21 - Dados de medição da implantação das parcelas da quadra "B" pelo método polar 


\begin{tabular}{|l|r|r|r|r|r|}
\hline ESTAÇ̃̃O & PONTO & DISTANCIA & AZIMUTE & E & N \\
\hline VRN-20 & & & & $749.885,7197$ & $6.934 .407,5044$ \\
\hline & VRN-6 & 137,623 & $26^{\circ} 00^{\prime} 58^{\prime \prime}$ & $749.946,0843$ & $6.934 .531,1823$ \\
\hline & DEP40010 & 112,408 & $165^{\circ} 48^{\prime} 34^{\prime \prime}$ & $749.913,2764$ & $6.934 .298,5268$ \\
\hline & DEP40011 & 87,980 & $182^{\circ} 15^{\prime} 10^{\prime \prime}$ & $749.882,2613$ & $6.934 .319,5923$ \\
\hline & DEP40012 & 77,929 & $185^{\prime} 7^{\prime} 08^{\prime \prime}$ & $749.878,7665$ & $6.934 .329,8860$ \\
\hline DEP40013 & 32,574 & $164^{\prime} 55^{\prime} 43^{\prime \prime}$ & $749.894,1896$ & $6.934 .376,0510$ \\
\hline DEP40014 & 18,121 & $115317^{\prime} 16^{\prime \prime}$ & $749.902,1039$ & $6.934 .399,7639$ \\
\hline DEP40015 & 29,085 & $56336^{\prime} 21^{\prime \prime}$ & $749.910,0030$ & $6.934 .423,5128$ \\
\hline DEP40016 & 51,139 & $39^{\prime} 02^{\prime} 39^{\prime \prime}$ & $749.917,9334$ & $6.934 .447,2223$ \\
\hline DEP40017 & 75,057 & $32^{\prime} 18^{\prime} 32^{\prime \prime}$ & $749.925,8362$ & $6.934 .470,9407$ \\
\hline DEP40018 & 114,568 & $27^{\circ} 28^{\prime} 25^{\prime \prime}$ & $749.938,5743$ & $6.934 .509,1516$ \\
\hline DEP40019 & 125,073 & $30^{\circ} 54^{\prime} 50^{\prime \prime}$ & $749.949,9755$ & $6.934 .514,8092$ \\
\hline DEP40020 & 134,561 & $43^{\prime} 16^{\prime} 18^{\prime \prime}$ & $749.977,9557$ & $6.934 .505,4799$ \\
\hline DEP40021 & 92,161 & $56^{\circ} 14^{\prime} 35^{\prime \prime}$ & $749.962,3428$ & $6.934 .458,7158$ \\
\hline DEP40022 & 149,373 & $53^{\prime} 35^{\prime} 19^{\prime \prime}$ & $750.005,9309$ & $6.934 .496,1690$ \\
\hline DEP40023 & 116,303 & $69^{\prime} 3913^{\prime \prime}$ & $749.994,7663$ & $6.934 .447,9424$ \\
\hline DEP40024 & 104,604 & $81^{\prime 3} 1^{\prime} 34^{\prime \prime}$ & $749.989,0999$ & $6.934 .423,4600$ \\
\hline DEP40025 & 98,101 & $9439^{\prime} 42^{\prime \prime}$ & $749.983,4479$ & $6.934 .398,9628$ \\
\hline DEP40026 & 97,213 & $100^{\circ} 45^{\prime} 30^{\prime \prime}$ & $749.981,2239$ & $6.934 .389,3562$ \\
\hline DEP40027 & 97,831 & $109342^{\prime} 23^{\prime \prime}$ & $749.977,8206$ & $6.934 .374,5158$ \\
\hline DEP40028 & 103,788 & $123^{\prime} 37^{\prime} 06^{\prime \prime}$ & $749.972,1484$ & $6.934 .350,0417$ \\
\hline DEP40029 & 119,646 & $138^{\prime \prime} 43^{\prime} 35^{\prime \prime}$ & $749.964,6449$ & $6.934 .317,5820$ \\
\hline DEP40030 & 65,020 & $133^{\circ} 06^{\prime} 50^{\prime \prime}$ & $749.933,1836$ & $6.934 .363,0666$ \\
\hline
\end{tabular}

Figura 22 - Dados de controle da implantação das parcelas da quadra "B" pelo método polar

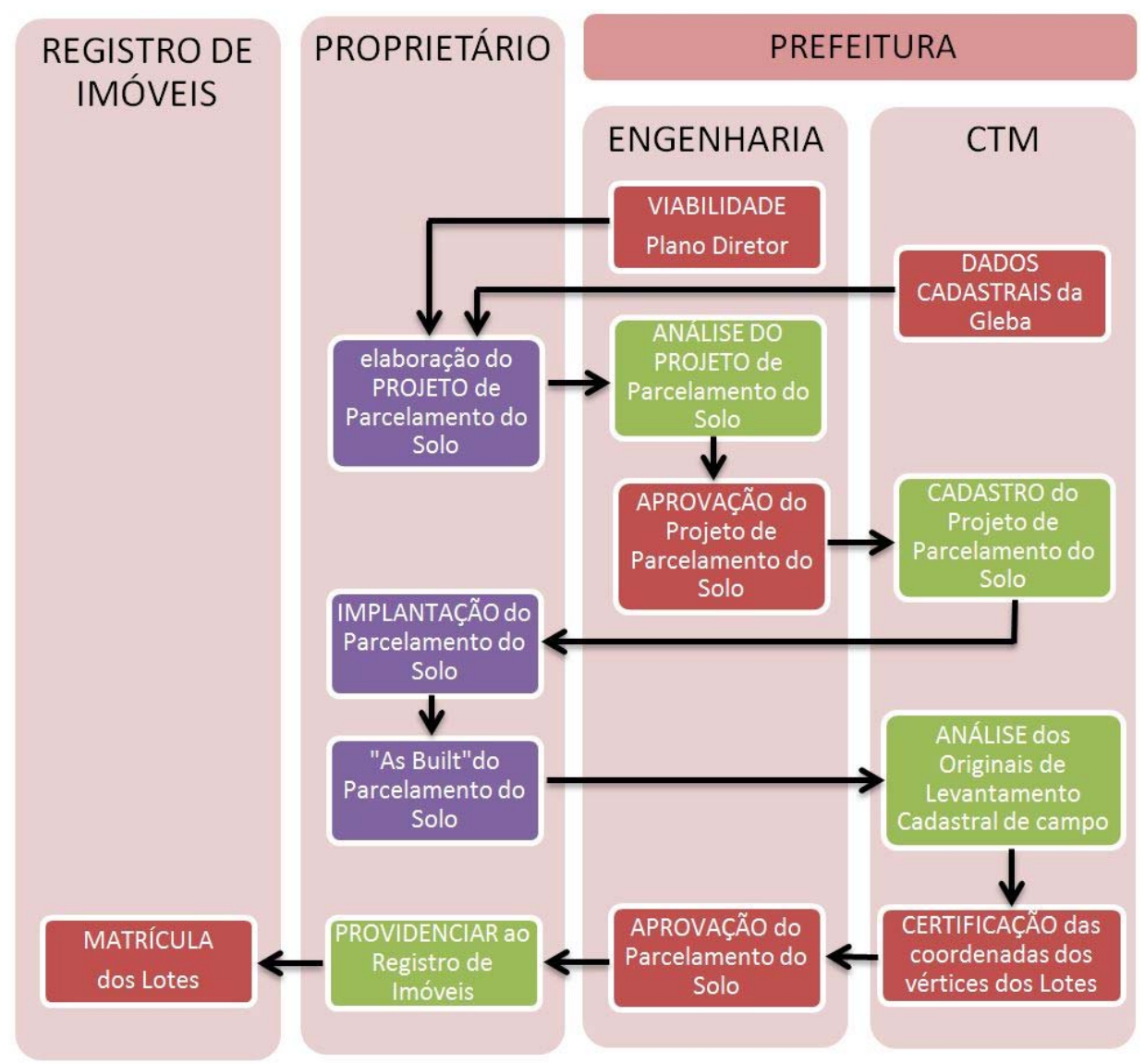

Figura 23 - Fluxograma para o cadastro do parcelamento do solo urbano 


\section{Conclusões}

Com os métodos e fluxogramas apresentados, as prefeituras através do CTM devem seguir estas diretrizes para fins de cadastro, com a elaboração de normas técnicas para implantação, controle e apresentação de documentos. Estas normas devem definir que informações e que dados devem ser entregues para a aprovação e certificação das coordenadas do parcelamento do solo urbano, quais sejam: as medições de demarcação e controles amarrados à RRCM, os croquis correspondentes, os cálculos e suas precisões e das propagações dos erros, métodos topográficos e geodésicos utilizados para os levantamentos e/ou implantação e controle, a codificação dos pontos dos limites legais das glebas e parcelas, e a codificação inequívocas das parcelas.

Estes dados devem ser organizados e arquivados pelo setor técnico do CTM, formado por profissionais habilitados e capacitados na área de cadastro para que possam ao final do processo homologar e certificar os pontos limites legais das parcelas e disponibilizar aos interessados que atuarem com o parcelamento do solo urbano.

Desta forma, o CTM consegue garantir e comprovar a localização dos pontos limites legais das parcelas urbanas, atendendo assim às exigências da Portaria $n^{\circ} 511$ (2009) do Ministério das Cidades.

Através da Câmara Federal, a Portaria nº 511 (2009), poderá ser transformada em Lei, para todo o território brasileiro.

\section{Referências}

ASSOCIAÇÃO BRASILEIRA DE NORMAS TÉCNICAS. NBR 13133: execução do levantamento topográfico - procedimento. NBR 13133. Rio de Janeiro: ABNT, 1994.

ASSOCIAÇÃO BRASILEIRA DE NORMAS TÉCNICAS NBR 14645-3: elaboração do “como construído" (as built) para edificações. Parte 3: locação topográfica e controle dimensional da obra - procedimento. NBR 14645-3. Rio de Janeiro: ABNT, 2000. 
BRASIL. Constituição da República Federativa do Brasil1988. Disponível em: < http://www.planalto.gov.br/ >. Acesso em: 16/07/2010.

BRASIL. Lei $\mathrm{N}^{\circ} \mathbf{.} 6.766$, de 19 de dezembro de 1979. Dispõe sobre o parcelamento do solo urbano e dá outras providências. Disponível em: < http://www.planalto.gov.br/ccivil_03/leis/L6766.htm >. Acesso em 03/04/2012.

BRASIL. Lei N 10.931, de 2004. Disponível em: < http://www.planalto.gov.br/>. Acesso em $16 / 07 / 2008$.

BRASIL. Ministério das Cidades. Gabinete do Ministro. Portaria n. ${ }^{\circ}$ 511, de 7 de dezembro de 2009. Diretrizes para a criação, instituição e atualização do cadastro territorial multifinalitário (CTM) nos municípios brasileiros. Diário oficial da união, Brasília, DF, 8 de dezembro de 2009.

HASENACK, M. A Cartografia Cadastral no Brasil. Tese (Doutorado). Programa de PósGraduação em Engenharia de Civil. UFSC. Florianópolis, 2013. 201 p.

Recebido em: 10/03/2015 Aprovado em: 30/04/2015

Universidade do Estado de Santa Catarina - UDESC 